\title{
MIGRACIÓN, ESTACIONAL EN EL NOROESTE ARGENTINO Y SU REPERCUSIÓN EN LA ESTRUCTURA AGRARIA
}

\author{
Carlos E. Reboratti \\ Fundación Bariloche
}

\section{Migraciones estacionales en Argentina}

EN EL MARco de la Argentina extra-pampeana y en las zonas tropicales y de oasis de riego del norte y oeste del país, se ha generado, desde fines del siglo pasado, una tendencia creciente de la producción de cultivos de tipo industrial y alimenticio caracterizados por requerir cantidades fluctuantes de mano de obra a lo largo del año, que coincide con los períodos de crecimiento y madurez de los cultivos. Así, en la época de siembra y crecimiento, los requerimientos son mínimos, mientras que en el momento de la cosecha la necesidad de mano de obra se multiplica de manera súbita para volver a descender cuando termina la cosecha (o zafra en sentido general). Estos requerimientos fluctuantes, de tipo estacional, han traído como consecuencia movimientos migratorios, mediante los cuales se cumple con esos requerimientos. Estas migraciones, por su carácter estacional y regular, son conocidas como "golondrina". Dentro de este esquema, podemos citar la cosecha de la manzana en Río Negro, el algodón en el Chaco, el tabaco en Salta y Jujuy y la caña de azúcar en Tucumán, Salta y Jujuy.

Por lo general, el origen de los migrantes es muy diverso y responde a las necesidades y características del sistema local de contratación de trabajadores: no sólo se moviliza población nativa, sino también migrantes provenientes de los países limítrofes, en especial de Bolivia, Paraguay y Chile. En el caso específico de los migrantes nativos, por lo general son las áreas deprimidas o marginadas las que actúan como emisoras de población: las áreas de minfundios, las de cultivos decadentes, las de cultivos de subsistencia y las reservas indígenas emiten año a año trabajadores hacia las zonas de cosecha. Algunos vuelven a sus lugares de origen al terminar ésta, otros se integran en un sistema circular de trabajo estacional, cuando encadenan varias cosechas, mientras otros utilizan la migración estacional como primer paso a la migración definitiva.

Este tipo de migraciones y sobre todo las que provienen de áreas mar- 
ginales, ${ }^{1}$ marcan el sistema de relaciones que se establecen entre éstas y lo que podríamos llamar el "resto del país", o sea el conjunto de la nación que se ha mantenido dentro del proceso de desarrollo general. En este trabajo, vamos a tratar de tomar un ejemplo de ese sistema de relaciones, y ahondar en la problemática de la irrupción de economías monetarias en áreas marginales de subsistencia y en especial en la estructura agraria de las mismas.

El trabajo se realizó con base en estadísticas oficiales, tanto nacionales como provinciales, el análisis de la escasa documentación existente en el área y, sobre todo, en los resultados de un viaje realizado a Santa Victoria (Provincia de Salta), en el verano de 1972, donde tuvimos la oportunidad de entrevistar a numerosos campesinos del área, así como a informantes calificados, tanto de Santa Victoria como de la capital provincial.

II. LA MANO DE OBRA para la zafra AZucarera en el VAlle del SAN FRANCISCO

Dentro del panorama general de la instalación agrícola de cultivos tropicales en el noroeste de Argentina, resalta el de la caña de azúcar. Existen dentro de la región dos áreas principales de cultivo que responden a dos tipos diferentes de estructura agraria. Una, la del Tucumán, numéricamente más importante (se siembra aquí el $69 \%$ de la superficie total de caña del país), se basa en la existencia de un número relativamente alto de ingenios de tamaño mediano (una producción media - para 15 ingenios- de 62300 toneladas), que por lo general compran la caña a pequeños y medianos propietarios independientes. Otra, conocida como "del Norte", y que agrupa a pocos ingenios, pero de tamaño considerable (cinco, con una producción media de 109600 toneladas) ${ }^{2}$ que muelen la caña que cultivan por lo general en terrenos propios. Estos ingenios se asemejan mucho, como veremos más adelante, a la estructura típica de "plantación". Ambas áreas utilizan importantes masas de mano de obra migrante en época de zafra. Así, año tras año los trabajadores estacionales afluyen al noroeste para permanecer en los campos de corte de mayo a octubre.

Interesa remarcar algunas particularidades que tiene la migración hacia el Valle del San Francisco, o sea la zona cañera que llamamos "del Norte" y, sobre todo, como dijimos, la relación que existe entre ésta y la estructura agraria del lugar de origen de un tipo específico de migrantes.

1 Cabe aclarar que entendemos como área marginal a toda aquella que ha quedado físicamente aislada del contexto nacional, por falta de integración al proceso de desarrollo nacional.

2 "El azúcar argentino en cifras, zafra 1973", separata de la revista La industria azucarera, Año LXXX, Núm. 973, diciembre de 1973. 
En general, hacia el Valle del San Francisco acuden tres tipo diferentes de migrantes estacionales, que responden a tres orígenes distintos y a tres formas diferentes de contratación, tanto como a actitudes y motivos de migración diferentes. El número total de migrantes es muy incierto, pero posiblemente oscile alrededor de 25000 trabajadores más las familias de algunos de ellos, por lo que el número total se encontraría alrededor de 40000 personas.

El primer tipo corresponde a los aborígenes. Estos provienen sobre todo del área de contacto con la región chaqueña, o bien del límite con Bolivia. Matacos, chiriguanos y chanés fueron los primeros trabajadores que, en el siglo pasado, fueron utilizados por los ingenios para la zafra. Constituyen el nivel más bajo en la escala de las condiciones laborales y su número desciende año a año, tanto por la disminución real de las poblaciones aborígenes nacionales, como por la tendencia de los ingenios a no utilizar este tipo de mano de obra. Estos grupos se encuentran en un proceso de marcada aculturación tanto en sus lugares de origen (cada vez más reducidos en tamaño) como en los ingenios. Este proceso tiende a confundirlos poco a poco con el campesinado nacional. Este tipo de mano de obra también se utiliza en la zafra algodonera y en los obrajes madereros de la selva. En sus lugares de origen, la mayor parte todavía se dedica a actividades de subsistencia, ya sea mediante la recolección y la caza ("marisquear" en términos locales) o bien mediante actividades agrícolas muy rudimentarias.

El segundo tipo es el de los migrantes provenientes del altiplano de Bolivia. Éstos son contratados en sus lugares de origen por contratistas volantes, que se encargan de conducirlos al lugar de trabajo. Se trata por lo general de campesinos de áreas empobrecidas, dado el medio hostil en el que se desarrollan, y que no permiten una ampliación de las áreas sembradas acorde con el crecimiento poblacional. Por lo general, se encuentran mejor pagados que los indígenas, pero sufren con frecuencia condiciones de trabajo extralegales, al amparo de su muy frecuente condición de migrantes ilegales. Este tipo de mano de obra tiende a ser utilizada cada vez con mayor frecuencia por los ingenios dado que of rece la ventaja para éstos de no participar prácticamente en la actividad gremial de los trabajadores del azúcar y, por ende, pueden ser tratados de manera arbitraria casi con total impunidad.

El tercer tipo, que más interesa para este trabajo, es el de los campesinos argentinos. Esta mano de obra adquiere mucha importancia en el análisis de las migraciones estacionales de la región, dado que en este caso se trata de movimientos intrarregionales: los trabajadores se mueven en un área relativamente pequeña, pero heterogénea en lo interno desde el punto de vista geográfico. Además, la relación entre áreas emisora y receptora de migrantes es mucho más directa e incluso, como veremos más adelante, partió de relaciones de superposición de estructuras agrarias diferentes. Estos trabajadores se encuentran en teoría amparados por 
las leyes laborales vigentes, si bien son frecuentes las transgresiones por parte de los ingenios. Posiblemente por el primer factor, éstos tienden a utilizar cada vez menos este tipo de mano de obra, tratando o bien de mecanizar la cosecha o bien aumentar el número de zafreros bolivianos.

Dada la posibilidad de completar un panorama amplio sobre el último tipo de trabajadores - los campesinos argentinos - y las características del lugar de origen, vamos a centrarnos exclusivamente en ellos, y de manera específica en un caso particular, el de los campesinos provenientes del Departamento de Santa Victoria (Salta).

\section{ANÁlisis GEOGRÁfICO GENERAL DE LAS ÁREAS DE RECEPCIÓN Y EMISIÓN DE MANO DE OBRA TEMPORARIA CAMPESINA}

Para tener una idea clara del tipo de relaciones que se establecen entre los ingenios del Valle del San Francisco y el área emisora de mano de obra campesina, por necesidad se debe partir de un análisis breve de las características geográficas de ambos, entendiendo esto en un sentido amplio, o sea el estudio de los sistemas de asentamiento humano.

En general, el área emisora cubre dos tipos geográficos diferentes: los valles altos y la Puna, ambos con características ecológicas distintas. Los valles altos, con climas templados y subtropicales moderados, son lugares aptos para la instalación agropastoril relativamente densa, basada en la producción (por lo general de autoconsumo) de maíz, papa y trigo y en la cría de pequeñas majadas de ovinos, caprinos y en ocasiones vacunos. Desde épocas precolombinas, estos valles han estado densamente ocupados (incluso en algunos casos estas poblaciones eran mayores que las actuales) por pueblos sedentarios. A la llegada de los españoles, se produjo una inserción de estos pueblos en el sistema general de colonización del noroeste, y más específicamente a través de la configuración de un sistema de haciendas (o latifundios). Este sistema se alargó hasta comienzos del presente siglo, merced a la falta de integración de toda la región al desarrollo general de Argentina. Recién cuando la economía del noroeste comienza a integrarse al resto de Argentina, poco a poco se van quebrando o marginando las economías de subsistencia y los latifundios se mantienen sólo gracias a su condición de receptáculos de mano de obra potencial. De todas formas, los diseños de asentamiento de la población rural no variạn en forma fundamental, y todavía hoy en día se articula en esas áreas marginadas con base en pequeños núcleos agrícolas ubicados en las zonas más aptas para la agricultura, y rodeadas de campos de pastoreo extensivo.

La Puna, en cambio, configura un ambiente geográfico del todo diferente. La hostilidad del clima, dada la gran altura de la zona, no permite el desarrollo de asentamientos densos y la poca población existente aprovecha algunos valles internos abrigados para desarrollar una agricultura muy precaria. La base económica se concentra en la ganadería ex- 
tensiva, tanto de lanares como de llamas y vicuñas. La Puna ha sido poco afectada en su estructura original de población. Sólo en ocasiones algún asentamiento minero se ubica en forma insular y atrae mano de obra de los alrededores. De todas formas, la capacidad de recepción de población del área es muy limitada. Esto se reflejó en las formas de configuración de las estructuras agrarias las cuales por lo general no llegaron a cristalizar en latifundios o, cuando esto sucedió, no sobrevivieron al siglo pasado. La población puneña, empujada por la necesidad, ya desde hace mucho tiempo se ha ocupado en tareas fuera de sus lugares de residencia, con el fin de complementar su economía: la explotación de la sal, o el pequeño comercio ambulante, son actividades comunes en la Puna y forman ya parte de la cultura local.

El área receptora de migrantes estacionales se ubica, como dijimos, en el Valle del San Francisco, que bordea el límite oriental del macizo andino y recorre terrenos mucho más bajos que la Puna o los Valles Altos. Esta posición hace que el clima tropical se extienda ampliamente, circunstancia que fue aprovechada para la instalación de cultivos de clima cálido. La población original estaba formada por cazadores y recolectores nómadas, eliminados ante el empuje de la instalación colonial. Los productos que se extraen de la región: bananas, mangos, hortalizas de primicia, caña de azúcar, etc., se destinan casi en exclusiva al consumo interno, de manera principal de la región Pampeana.

$\mathrm{La}$ instalación de los ingenios azucareros en la región, a fines del siglo pasado, responde a iniciativas de capitales locales, que se basaron en el mayor rendimiento potencial de la caña en relación a la de Tucumán. En general, el tipo de estructura basada en la caña de azúcar responde a la forma de "plantación", grandes extensiones de tierra, monocultivo de tipo tropical, preferencia por mano de obra migrante, capital inicial intensivo, subutilización de parte de la tierra, producción exclusiva de exportación. La única salvedad que podemos hacer es que, en este caso, se trata en realidad de una producción destinada no a la exportación fuera del país, sino al consumo del mercado interno. Esto trae aparejado que la toma de decisión no se hace en el exterior, sino que responden a intereses locales. De todas formas, esto no afecta por necesidad la estructura de funcionamiento de la plantación. Incluso estas plantaciones atravesaron los períodos que señala Diéguez Jr., ${ }^{3}$ desde propiedades familiares o personales hasta sociedades anónimas.

Una vez caracterizadas de esta forma las tres áreas, interesa remarcar que las relaciones más fuertes se van a entablar entre los Valles Altos y el Valle del San Francisco mediante el traspaso de población migrante de una u otra área. La Puna también participa de esta relación, pero desde un principio lo hace en forma más laxa, a través del trabajo de

3 M. Diéguez Jr., Establecimientos rurales en América Latina, Eudeba, Buenos Aires, 1967, Cap. V. 
contratistas. En cambio, latifundios y plantaciones van a formar una estructura más sólida. Sobre esta relación haremos hincapié.

\section{LAS MIGRACIONES ESTACIONALES CONSECUENTES DE LA RELACIÓN- PLANTACIÓN-LATIFUNDIO}

La situación inicial esbozada es la de una plantación que necesita cierto volumen de mano de obra estacional para su funcionamiento, y un latifundio que posee en su interior una gran cantidad de población rural dispersa, en condiciones de subsistencia. Es importante señalar además, que tanto la plantación como el latifundio, pertenecen en una primera etapa al mismo grupo de familias salteñas y jujeñas, con amplia comunidad de intereses, y que configuran uno de los grupos oligárquicos de mayor poder político y económico del noroeste de Argentina.

El problema básico es, entonces, determinar un mecanismo de captación de esa población rural para utilizarla en la zafra. Un análisis muy general indicaría que el mecanismo puede ser simple: dado que las poblaciones de los valles altos concentran sus tareas agrícolas entre fines de primavera y mediados de otoño, y que justamente éste es el lapso de menor trabajo en la zafra, se podría pensar en una especie de economía complementaria, donde el campesino trabaja de mayo a octubre en la caña de azúcar, y de noviembre a abril en sus cultivos tradicionales, y se mueve de manera alternativa entre uno y otro lugar.

Pero existen una serie de impedimentos para habilitar este mecanismo: por ejemplo, la época invernal es la utilizada por los campesinos para realizar las tareas de limpieza y ampliación del área sembrada, fabricación de artesanías, etc. Por otra parte, el campesino posee en este caso un gran arraigo a su tierra, y no tiene ningún interés en movilizarse para ganar dinero que no necesita, dado que de hecho vive de lo que produce y su arriendo lo paga en especie.

Para solucionar estos inconvenientes, el ingenio apela entonces a un sistema menos libre, pero más seguro: la plantación arrienda en bloque el latifundio y se transforma de hecho en dueña de la vida y el trabajo de los campesinos que viven en esas tierras. Éstos se ven obligados a subarrendar sus campos, pero el pago ahora debe ser en dinero. Si todavía algún campesino se niega a migrar hacia la zafra, queda el recurso de la fuerza (que fue finalmente el utilizado en una primera etapa).

Este sistema de relación se entabló a partir de alrededor de 1920, específicamente en toda el área que limita entre la Puna y los Valles bajos y abarcaba por lo menos los Departamentos salteños de Santa Victoria e Iruya. Tomaremos al primero como ejemplo, para ver como fue evolucionando la situación y de qué forma fueron afectadas las estructuras agrarias locales. 
V. Santa Victoria: características del asentamiento de la poBLACIÓN Y LA ESTRUCTURA AGRARIA HASTA 1920

Vamos a referirnos entonces en forma específica a un ejemplo concreto de lo que se plantea antes. Para poder ubicarnos en el contexto particular del lugar, se hace una caracterización general de las condicio-

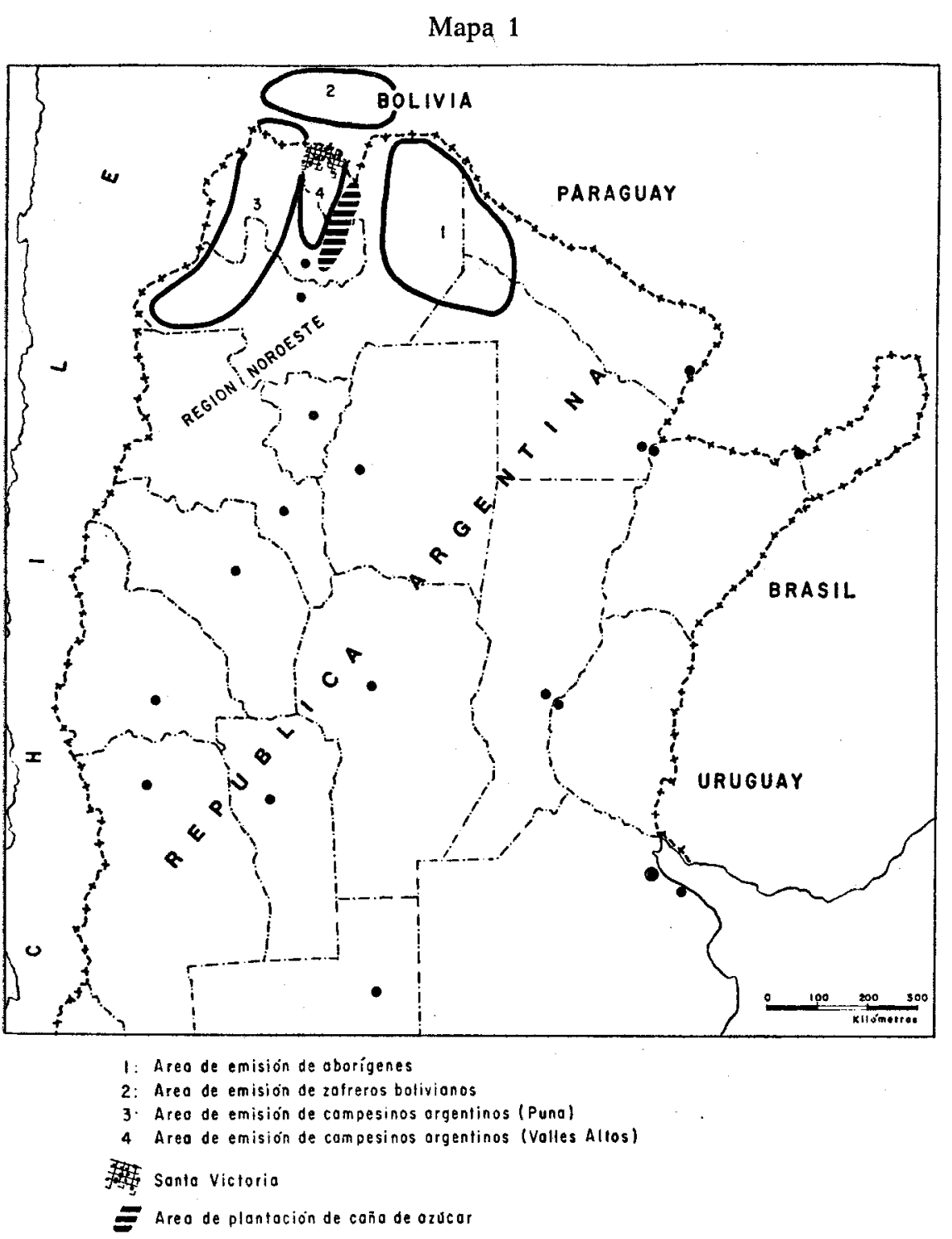


nes de asentamiento de la población local. Vamos a verla como el resultado de la marcha de un proceso histórico de las estructuras agrarias locales, en un área geográficamente aislada del entorno nacional. Santa Victoria es un Departamento (unidad mínima administrativa de la República Argentina) de alrededor de 4000 kilómetros cuadrados, localizada en el ángulo noroeste de la República (véase el mapa 1). Se encuentra ubicada entre dos regiones diferentes, que ya hemos descrito: la Puna y los Valles bajos. Esta posición hace que las características naturales del lugar sean muy contrastantes en relativamente poco espacio: a medida que se desciende hacia el este desde el borde de la Puna, a 4500 metros de altura, las condiciones de aridez del clima de alta montaña disminuye y, entre alrededor de 3000 y 1500 metros se tiene una franja de climas templados, con lluvias estivales intensas y una larga sequía en invierno. Esto afecta en forma directa el régimen de los cursos hídricos, muy irregular y de manera indirecta, obliga a un manejo muy cuidadoso de los terrenos de cultivo, dado que el poder erosivo de las precipitaciones es importante (en cultivos de ladera, una parcela produce sólo durante tres años, al cabo de los cuales el suelo ha desaparecido casi totalmente). Además, el poder erosivo de los ríos es tal, que ha configurado un paisaje sumamente quebrado, que dificulta las comunicaciones tanto internas como externas. Más hacia el este, la selva cubre las serranías en pisos descendentes de gradual intensidad, hasta llegar a formar en el fondo de los valles masas impenetrables. Estas tres regiones diferentes se dan a lo largo de una línea de no más de 70 kilómetros.

O sea, existen en verdad dos factores de marginación física que enmarcan la única zona realmente apta para la instalación humana: la alta montaña y la selva que configuran una situación de difícil comunicación con el exterior.

La población se concentra sobre la franja central, mientras que las otras dos permanecen casi despobladas (véase el mapa 2).

También la situación de Santa Victoria con respecto a los centros de decisión ha influido en su actual situación marginal: arrinconada sobre la frontera boliviana, ningún camino vincula de manera directa a Santa Victoria con el resto de la Provincia a la cual pertenece; apenas un difícil camino de cornisa la vincula recién a partir de 1962 con La Quiaca, al norte de la Puna y en la provincia de Jujuy.

La población original estaba formada por agricultores-pastores sedentarios, con un nivel cultural avanzado, que se reflejaba en la "sofisticación" de las técnicas de manejo de canales de riego y terrazas de cultivos, o en la construcción de sólidas habitaciones de piedra.

La llegada de los españoles no afectó demasiado esta población e introdujeron sólo algunos cambios en los tipos de cultivo (trigo, alfalfa) y en el ganado (vacunos y ovinos). La estructura de asentamiento no fue modificada, lo que cambió fue la situación de los indígenas, que pasaron a ser arrenderos de pequeñas parcelas pagadas en especie o en trabajo: 
Mapa 2



Referencios

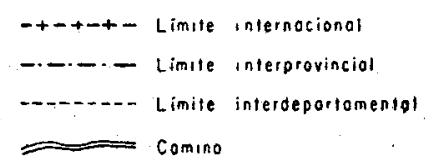

(*) 10 habitontes

(1) Allo montoño

(2) Volles altos

-4000- Cufvo de nivel

(3) Valles bajos - selvo

Las tierras fueron repartidas en un principio entre varios españoles, pero después, poco a poco se concentraron en una sola familia, hasta convertirse en un enorme latifundio pertenencia del Marqués de Tojo (conocido localmente como Marqués de Yavi, por estar ubicada en esta localidad pequeña el casco principal del latifundio). Este excedía los límites de Santa Victoria y abarcaba tanto áreas de la Puna como de selva. Durante la época del Marquesado, la población indígena mantenía prácticamente una economía de subsistencia, dado que el contacto con el exterior era casi nulo y, cuando sucedía, era a través de los administradores de la finca. La estructura agraria estaba configurada entonces, por 
un latifundio que arrendaba parte de sus campos a una población indígena, minifundista, que utilizaba dichas parcelas para el cultivo y explotaba en forma comunal los campos de pastoreo. La población estaba de manera absoluta dominada por la autoridad del latifundista.

Para fines del siglo pasado, vivían en Santa Victoria 3700 personas, 512 de las cuales eran arrendatarios y el resto familiares de los mismos. La estructura de la población era regular, de tipo piramidal muy ancha en la base, indicio de elevadas tasas de mortalidad infantil y esperanza de vida corta.

Para 1914, el censo de población indicaba alrededor de 4200 personas. El crecimiento no parece muy grande (el 6.9 por mil anual) pero el problema de manejar cifras censales de estas áreas, es el posible error que puede surgir de un censo realizado en condiciones muy desfavorables, más aún en 1900. Se utilizan entonces las cifras censales con serios reparos.

Las técnicas de producción actuales, reflejan aun de manera fiel las características de este período. Son totalmente rudimentarias y los cultivos se basan en dos sistemas: los cultivos irrigados de fondo de valle, realizados sobre suelos bien desarrollados de origen aluvial, que se trabajan con sistemas de barbecho rotativo, se cultivan papa, maíz de diversos tipos, trigo y en ocasiones algunas legumbres; y los cultivos de faldeo, de tipo de secado, realizados sobre suelos poco desarrollados y sueltos. La eliminación de la cubierta vegetal original que sostiene esos suelos, y el posterior removido del arado, disgregan aún más el suelo, que es lavado rápidamente por las lluvias estivales, aun cuando los campesinos aran, por tradición, las parcelas en el sentido de las curvas de nivel. Esto obliga a un cultivo itinerante de ciclo abierto, dado que el suelo no vuelve a regenerarse en un lapso razonable. Los tipos de cultivo son los mismos. En ambos casos, no hay selección de semilla ni aporte de semillas desde el exterior, lo que degenera poco a poco las especies.

El ganado se cría a campo abierto, sin ningún tipo de apotreramiento, el campesino se limita a soltar a los animales durante la primavera y el verano para aprovechar las pasturas naturales (por lo general, de noche encierra al ganado menor como prevención contra los animales depredadores). Ovinos y caprinos permanecen todo el año en los valles altos, dada su mayor resistencia al frío y sus menores requerimientos de pastura. Los vacunos, en cambio, son bajados a los valles cálidos del este en invierno. Este traslado se hace en forma comunitaria, rotativamente las familias se encargan año con año de juntar los rebaños y bajarlos a la selva donde son dejados desde mayo a septiembre. En este último mes, son conducidos de nuevo hacia los valles altos. Durante su permanencia en la selva los animales se alimentan de los escasos pastos del sotobosque, pero son atacados por toda clase de enemigos, sobre todo por el vampiro, que les transmite el virus de la fiebre paresiante (conocida como "rabia"). 
Antes de 1920, existían alrededor de 2.1 animales por cada persona en Santa Victoria.

La población fabricaba ponchos, telas gruesas, ojotas de cuero, instrumentos de labranza, molía el trigo en el viejo molino hidráulico de Santa Victoria y, en general, se movía en un universo reducido y de autosubsistencia. Las relaciones del campesino con el latifundista eran, como ya dijimos, de total sumisión. Los descendientes del Marqués de Tojo mantenían su posesión como un feudo personal, cobrando bajos arriendos en trabajo o especie.

Esta era, a grandes rasgos, la situación local hasta 1920. Algunos de estos elementos aún subsisten, otros fueron modificados de manera sustancial por la introducción de la economía monetaria y el trabajo estacional.

\section{LAS ETAPAS DE LA RELACIÓN PLANTACIÓN-LATIFUNDIO Y SU REPER- CUSIÓN EN SANTA Victoria}

Al llegar a este punto, conviene analizar con mayor profundidad las características de las dos estructuras agrarias que hemos delimitado y enmarcarlas dentro de la tipología común para estos análisis.

La plantación cañera del Valle del San Francisco, como hemos visto, no se aparta demasiado de las definiciones clásicas al respecto, salvo en el punto de la no exportación del producto elaborado. Sucede que la República Argentina posee un mercado interno lo suficiente desarrollado (concentrado sobre todo en el área pampeana) como para permitir producciones de cierta escala. Además, aclaremos que existe en verdad una forma de colonialismo interno de la región pampeana-litoral con respecto al interior, por lo que las decisiones que se toman con respecto al manejo de las plantaciones, al hacerse en Buenos Aires, actúan en realidad como provenientes de un centro de decisión "externo" a los intereses de la región.

En los últimos años, se ha producido un proceso de modernización acelerada en las plantaciones más grandes, coincidente con el gradual traspaso de los capitales de las familias tradicionales locales a grupos financieros nacionales, residentes en Buenos Aires. Este proceso abarca desde la utilización integral del rezago de caña de azúcar para fabricar papel, hasta la mecanización de las tareas agrícolas, entre ellas la zafra. Este último hecho tiende a independizar a los ingenios de la mano de obra migrante, pero parecería ser que el proceso no es rápido, sobre todo por la oposición que encuentra por parte de los trabajadores organizados.

Esta modernización no alcanza, como dijimos, a todos los ingenios del lugar, dado que dos de ellos (los más pequeños) todavía se mantienen con las formas de producción de principios de siglo. El tamaño de las plantaciones es considerable: entre 1963 y 1973 se sembró una media anual, entre los 5 ingenios, de 46600 hectáreas de caña, poco más de 
9000 por ingenio. Por otra parte, la superficie sembrada con caña es siempre mucho menor a la efectivamente poseída por la plantación. Éstas por lo general amplían sus límites mediante la compra y el talado de superficies boscosas $y$, en ocasiones, dedican cierta cantidad de parcelas a la producción de cítricos o frutas tropicales. En cuanto al latifundio, que sirve de marco de emisión a los. zafreros, se aproxima bastante al tipo de "hacienda" definido por Solomon Miller ${ }^{4}$ como tipo 1 para el Norte del Perú, o sea una antigua propiedad arrendada o comprada por una estructura más moderna, pero que no introduce mayores cambios en ella y utiliza la mano de obra contenida en la misma; con la única salvedad a esta caracterización, de la ausencia de excedentes comercializables de tipo agrícola. En realidad, se trata de un latifundio "congelado o cristalizado" mediante el arriendo a otro tipo de empresa, en nuestro caso una plantación. La extensión original del latifundio oscilaba alrededor de 220000 hectáreas y contenía alrededor de 3000 arrenderos. Es necesario profundizar todavía más el estudio sobre las relaciones pasadas y presentes entre los propietarios del latifundio y sus arrendatarios, pero en líneas generales lo expresado puede servir como referencia.

\section{La etapa original (1920-1940)}

La primera fase de las relaciones entre latifundio y plantación, se puede ubicar entre 1920 y 1940 . En la primer fecha, uno de los ingenios del Valle del San Francisco decide arrendar a la finca Santa Victoria en su totalidad; en la segunda, cesa de obligar a los victoreños a dirigirse a la zafra. Como hemos dicho, la necesidad de obtener mano de obra lleva al ingenio a buscar a la población de las zonas altas. La introducción del ingenio en Santa Victoria, es muy importante para la estructura interna local. E1 mecanismo de reclutamiento de que se vale el ingenio es simple: dado que ha reemplazado al latifundista en su papel de dueño y señor, obliga a los campesinos mediante la fuerza a enrolarse para la zafra. La impunidad es total y es incluso la policía misma la que cumple la función coercitiva. Gran parte de la mano de obra masculina (alrededor del $50 \%$ de los hombres de todo el Departamento) se desplaza hacia los valles cálidos del Este. Esto trae dos consecuencias inmediatas: primero, la introducción forzosa de la población en una economía monetaria; segundo, se anula o disminuye la capacidad de ampliación de la superficie sembrada, debido a que la fuerza de trabajo masculina es desplazada en los meses que se dedican por lo general a las tareas de ampliación de los cultivos. El traslado de los hombres en el invierno no afecta en sí las tareas de cultivo, que en estas áreas se realizan a partir

4 Solomon Miller, "Hacienda to Plantation in Northen Peru", en J. Steward (Comp.), Contemporary Change in Traditional Societies, Vol. III, Universidad de Illinois, 1967. 
de mediados de octubre, pero coartan del todo la posibilidad de ampliación.

El otro punto importante era, entonces, el de la introducción en Santa Victoria de una economía monetaria. Vimos que hasta 1920, en la práctica el lugar se movía en un universo autosubsistente y si había algún intercambio, éste era del tipo de trueque. Prácticamente no se conocía el dinero, o al menos su circulación era muy escasa. Al ser los hombres obligados a ir a la zafra y encontrarse con que comienzan a cobrar dinero por su trabajo, se produce una brusca irrupción del dinero en Santa Victoria. Con lo que ganan (que no es mucho por otra parte) los victoreños compran productos industriales, que poco a poco reemplazan a las artesanías. Decae por ende este tipo de tareas que, por otra parte, se realizaban en especial durante el invierno. Los zafreros también compran comida para complementar en parte lo que no pueden producir. La circulación creciente de dinero trae también como consecuencia un aumento en la importancia de comercio minorista local, encargado de proveer a los victoreños los artículos de consumo y alimentos que ya no producen.

La migración a la zafra no afecta en cambio a la actividad ganadera, dado que es un tipo de tarea que no insume mayor cantidad de mano de obra masculina, pues el cuidado de los rebaños es una tarea llevada a cabo por niños y mujeres.

El ingenio no introduce ningún tipo de modificaciones directas en la estructura agraria interna de Santa Victoria, se limita a reemplazar al latifundista en el papel de arrendador, pero ahora el cobro se hace en dinero.

Según los datos disponibles, la suma cobrada en concepto de arriendo no es mucha, pero suficiente como para obligar al arrendatario a disponer de cierta cantidad de metálico cada año. La modificación de la estructura agraria se dará como repercusión al coartar la capacidad de ampliación del cultivo de subsistencia.

No existen en esta etapa datos específicos con respecto a la población, pero al interpolar entre 1914 y 1947, oscilaría alrededor de las 6000 personas. En 1937, existían según el Censo Agropecuario de ese año, 1.5 vacunos y 8.7 ovinos por habitante. Al comparar con 1895 , o sea el período anterior al ingenio ( 2.1 y 8.2 , respectivamente) se observa que la relación de ovinos se mantiene y la de vacunos ha descendido un tanto. Los datos de los cultivos no son en absoluto confiables, dado que no se censan las parcelas chicas, base para la subsistencia local. ${ }^{5}$

La primera etapa comienza a trastocarse en otra, cuando suceden dos cosas: primero, poco a poco desaparece la coacción física para ir a la zafra, segundo, los zafreros comienzan a ser acompañados por sus familias o parte de ellas.

5 El mismo Censo Agropecuario de 1937 indica que de 3000 trabajadores rurales, sólo $15 \%$ recibe salarios, el resto son familiares de los productores. De 1200 explotaciones censadas, 1100 eran arrendadas. 
El porqué de la desaparición de la coacción física puede ser tema de discusión. De manera objetiva, parecería que los campesinos, una vez introducidos de lleno en una economía monetaria, el solo efecto de cadena les imposibilita volver a su situación primitiva y, por lo tanto, los lleva a seguir con el trabajo en la zafra para obtener una mínima cantidad de dinero. Además, no olvidemos que el ingenio mantiene el arriendo sobre la finca y cobra sus arriendos a los campesinos. Dado que para éstos es casi imposible conseguir dinero a partir de su producción agrícola o ganadera por la inexistencia de mecanismos de comercialización de excedentes (además, éstos prácticamente no existen), se ven entonces obligados a recurrir a la zafra como forma de mantener su dominio sobre las parcelas de cultivo.

\section{La etapa del contratista y el fin del arriendo (1940-1965)}

Una vez que cesa la acción policial y el ingenio se ha asegurado la necesidad de los campesinos de concurrir a la zafra, el ingenio conforma un nuevo sistema de reclutamiento. Se instala entonces en Santa Victoria un contratista dependiente del ingenio. Su tarea consiste en reclutar trabajadores de acuerdo a cierto cupo de plazas por año que el ingenio le indica. Esto le da al contratista un enorme poder sobre los campesinos, dado que se constituye de hecho en el único administrador de su trabajo. En esta etapa, Santa Victoria se asemeja más a las formas de reclutamiento de campesinos de la zona puneña, pero con la particularidad de que en este caso el contratista es a la vez el principal comerciante del lugar (tal vez la relación sea causal entre ambas circunstancias).

Conviene aquí describir con brevedad las condiciones de contratación y trabajo de los victoreños en esta etapa. El contratista exige de manera usual a los peones la apertura de una cuenta considerable en su comercio, como condición para anotarlos en las listas de trabajo, hecho prácticamente considerado como una "cuota de ingreso" a la zafra. Si a esto se suma el hecho usual de que el campesino compra mercaderías a lo largo del año, a cuenta del trabajo zafral, veremos que ya antes de ir a la zafra, el campesino tiene una deuda considerable con el almacenero-contratista. Una vez iniciado el trabajo de zafra (a donde el peón es llevado por el contratista primero en mula hasta la Quiaca y desde allí en tren) el encargado de recibir los sobres con el sueldo es el contratista y no el peón. Aquél quita del jornal lo que considera que el campesino le adeuda, y lo mismo hacen todos los almaceneros de Santa Victoria, que se han trasladado al ingenio sólo para cobrar sus deudas. Se suman además el cobro del arriendo de las parcelas agrícolas y los pastajes. A todo esto, el campesino debe además comprar en exclusiva en los comercios ubicados dentro de la plantación durante su período de trabajo (esta particularidad se mantuvo aproximadamente hasta 1950). Ya a esta altura del jornal original queda muy poco. Si además se considera 
que el victoreño debe comprar lo que no puede ya fabricar con sus manos (ropas, zapatos, etc.) caeremos en cuenta que, al volver de la zafra, el campesino no posee demasiado dinero. Para 1947, por ejemplo, el peón volvía a Santa Victoria con alrededor de lo que hoy serían 190 dólares, después de siete meses de trabajo. ${ }^{6}$

Esta magra suma le obliga en un plazo breve a reabrir un crédito con los comerciantes de la zona y el ciclo vuelve a reiniciarse.

Por otra parte, la vida en el ingenio es muy dura, casi rozando los límites de la esclavitud. En los primeros momentos, como ya dijimos, incluso se prohíbe a los zafreros comprar mercaderías fuera de los límites de la plantación. Con el mejoramiento de las leyes laborales, las condiciones. cambian poco a poco, pero la plantación siempre trata de sacar ventajas a los peones. Por ejemplo, cuando la ley dice que el ingenio debe proporcionar al contratado una cierta superficie cubierta para vivienda, se especifica que esa superficie corresponde a cada libreta de trabajo. Ahora bien, cada trabajador (o sea cada libreta) es acompañado por lo general por dos o más personas (sus familiares), pero el ingenio se limita a cumplir con la letra de la ley. Así, en una habitación donde legalmente deben vivir cuatro personas, conviven durante siete $\mathrm{u}$ ocho meses doce o más, incluidos mujeres y niños. Las mujeres acompañan a sus esposos a la zafra de manera principal para prepararles el alimento diario y en ocasiones ayudarlo en la tarea junto con los hijos mayores. El alimento consiste principalmente en maíz y papas, que la mujer transporta al surco al mediodía y prepara en las precarias habitaciones durante la noche.

Por lo general, no hay ningún tipo de confort ni control sanitario en las habitaciones de los obreros, todas las personas entrevistadas manifestaron que al estar en la zafra el contagio de todo tipo de enfermedades, sobre todo las infecciosas, era muy común.

Como hemos dicho, en Santa Victoria, el ingenio, a pesar de haber cambiado el sistema de reclutamiento, mantiene el arriendo como forma de asegurarse la necesidad de dinero de los arrendatarios. Los arriendos son bajos todavía. El informe de 1947 que antes nombramos, señala que se pagaba el equivalente actual de 43 dólares por hectárea cultivada, 10 por vacuno como derecho a pastaje y 70 por cada 100 ovejas o cabras. $\mathrm{O}$ sea que un arrendero promedio que tuviera una hectárea cultivada, dos vacas y 100 ovejas, pagaría alrededor de 175 dólares por año de arriendo y derecho de pasturas.

El ingenio mantiene esta situación hasta 1962, cuando decide romper el vínculo de arriendo con la Finca Santa Victoria. En el lapso de más de 40 años de arriendo, la plantación no ha invertido un solo peso en la finca, y la ha mantenido en exclusiva como reserva de mano de obra. Pero a pesar de la desvinculación total, los campesinos aún asisten

6 Ministerio de Acción Social y Salud Pública de la Provincia de Salta, "Los Departamentos de Santa Victoria e Iruya", Salta, 1947. 
a la zafra, y el contratista se constituye en definitiva en el dueño de la situación.

Se ve entonces como, a lo largo de las dos primeras etapas, la plantación actúa como "congeladora" de la estructura agraria local, que sólo va a dinamizarse al romperse los vínculos de arriendo.

\section{La reducción de los cupos de trabajo}

Entre 1962 y 1968, se superponen dos procesos, uno interno y otro externo a Santa Victoria, que afectan de manera profunda el sistema de relaciones ya descrito. En primer lugar, ante una amenaza de expropiación por parte del senado de la provincia de Salta, los propietarios de la Finca Santa Victoria deciden vender los terrenos. En segundo lugar, pocos años más tarde el ingenio decide reducir de manera drástica la cuota de trabajadores requeridos al contratista local. Entre 1967 y 1970, se pasa de 900 libretas de trabajo (o sea una migración efectiva que bordeaba las 3000 personas) al contar a los familiares de los zafreros, a 500 libretas o menos.

El porqué de esta medida puede deberse tanto al proceso de mecanización de la zafra, como al posible traslado del cupo de trabajo a los migrantes bolivianos, que, como vimos, convienen más a los intereses del ingenio.

El problema de la venta de terrenos de la finca es complejo, y va a afectar profundamente el sistema de tenencia del lugar. En principio, los propietarios de la finca se habían comprometido a vender únicamente a los arrendatarios, a precios muy bajos, y con las mensuras realizadas. Los terrenos en efecto se venden, pero bajo condiciones distintas.

Esta cuarta etapa marca el fin de la relación entre una y otra estructura agraria: por un lado la plantación ya no necesita del arriendo, por otro, el latifundio, sin la "protección" que le significa el arriendo, tiende a disolverse.

\section{LA CRISIS DE LA RELACIÓN Y SU REPERCUSIÓN EN SANTA VICTORIA}

Los efectos que tienen en Santa Victoria los dos últimos procesos, son múltiples. En primer lugar, la reducción de la cuota de trabajo coloca a los trabajadores estacionales ante un problema crítico: no conocen otro sistema de colocación laboral que el definido a partir del contratista y, además, los ingenios sólo trabajan con este sistema a fin de asegurarse mutuamente la inmovilidad espacial de la mano de obra, con lo que se evita una presión sobre el aumento de salarios. Por otra parte, la falta de excedente en la producción interna del Departamento en este siglo, no permite el desarrollo de actividades remunerativas. El número de animales por habitante se mantiene constante en 1960 con respecto a 1937, e incluso desciende, en 1969, a 1.2 vacunos y 5.2 ovinos por ha- 
bitante. No parece existir una tendencia seria hacia la producción especulativa de ganado. La mayor parte de los victoreños no posee un acerbo de ganado que le permita organizar un sistema continuo de ventas. Consideremos, por ejemplo, que un animal puede tardar alrededor de nueve años en alcanzar 300 kilos de peso. Las enfermedades son comunes y no hay mejoramiento de razas (la totalidad de los animales pertenece a la raza conocida como "criolla"). Los pocos animales que se venden, son traficados en forma ilegal con compradores bolivianos que envían el ganado en pie, de contrabando, hacia el sur de Bolivia.

Por otra parte, aun cuando el victoreño dispusiera de excedentes agrícolas, con dificultad los podría vender, dado que el transporte hacia los mercados potenciales es demasiado caro y difícil.

La virtual imposibilidad de obtener dinero lleva a los victoreños a una disyuntiva: volver a la actividad de subsistencia o migrar definitivamente.

La primera posibilidad parece bastante remota: el sistema de tenencia de la tierra ha cambiado, el latifundio original casi no existe. La ignorancia o la necesidad de los campesinos los lleva a aceptar trasladar sus derechos de compra a los comerciantes, en especial al contratista. Éste, ante la reducción de lá demanda de trabajo, ha aumentado su "cuota de ingreso" y con frecuencia obliga al campesino a cederle además sus derechos sobre la tierra. Los pocos victoreños que compran se encuentran ante la falta total de mensuras, lo que otorga un valor prácticamente nulo al contrato de compraventa. Además, el círculo se cierra dado que el no ir a la zafra, les impide conseguir dinero como para adquirir una propiedad. Por otra parte, los precios reales se han incrementado a niveles mucho mayores que los originales.

Este proceso lleva a la concentración de la tierra a manos de los comerciantes, que poco a poco van reemplazando como terratenientes a la familia latifundista. Las motivaciones de uno y otro son totalmente distintas: mientras que la familia tradicional se limitaba a utilizar su propiedad como bien de especulación y dominación social más que como bien de producción, los comerciantes tratan de sacar el mayor provecho posible a las tierras, por lo general mediante la ampliación de los rebaños.

Todos estos factores interrelacionados casi podemos decir que obligan a la población a una migración definitiva: entre 1960 y 1970, emigra definitivamente el $10 \%$ de los victoreños. Obligados a abandonar sus tierras, se enfrentan a un destino incierto: una parte de ellos se traslada a los valles del sur, para trabajar en la cosecha del tabacó, otros se asientan definitivamente en el Valle del San Francisco, otros irán a engrosar las poblaciones marginales de las grandes ciudades. 


\section{LAS ÁREAS MARGINALES, LA INVESTIGACIÓN Y LAS SOLUCIONES}

Hemos tratado en este trabajo de ejemplificar el sistema de relaciones entre dos estructuras agrarias diferentes, a través de la mano de obra migrante, y cómo este sistema ha incidido en la producción de una profunda crisis en el área emisora de migrantes. Creemos que el caso es válido para ampliar a otras áreas.

Podemos señalar a Santa Victoria como un ejemplo de la crisis que atraviesan la mayor parte de las áreas geográficamente marginadas de Argentina: utilizadas por lo común como reserva de mano de obra no especializada, su destino es sufrir las alternativas del proceso de tecnificación de la producción agropecuaria. Estas áreas no han desarrollado una estructura capaz de acompañar el crecimiento demográfico con un aumento de la producción, es decir, que el autoabastecimiento no se mantiene. Tampoco se han integrado en forma normal al proceso general de desarro1lo, salvo en los casos de que ofrezcan recursos naturales de interés para la coyuntura económica. ${ }^{7}$

Su carácter de marginalidad espacial se refleja no sólo en las deficiencias del sistema de comunicaciones con el exterior: en estas áreas las herramientas normales de la investigación no son confiables. Por ejemplo, como dijimos, el Censo Agropecuario no considera dentro de sus cómputos las parcelas menores a una hectárea destinadas al autoconsumo. Pero en lugares como éste, justamente estas parcelas son las que importan. Por otra parte, el Censo de Población se realiza de manera normal en septiembre, o sea plena época de zafra: sólo se censan en Santa Victoria a los que han quedado, mientras que los zafreros y sus familias se censan en la plantación. Para un observador desprevenido, la estructura de la población puede indicar, por ejemplo en 1960 o 1970 una enorme migración masculina adulta, pero si se hiciera el censo en verano, con seguridad la estructura cambiaría en forma radical. En estas áreas, tenemos que manejarnos con información proveniente de otro tipo de fuentes: informantes calificados o encuestas (si bien éstas son bastante difíciles de realizar dada la dispersión de la población y las dificultades del terreno).

Las áreas aisladas se constituyen en una especie de museo de condiciones generalmente pasadas, como en el caso de las formas de asentamiento de la población.

Es difícil tratar de plantear algún tipo de solución para las áreas aisladas. Por lo general, los resultados de años y años de marginación han afectado profundamente la estructura productiva de la zona. La solución simplista de romper el aislamiento mediante la construcción de

7 Para ampliar este tema y el de Santa Victoria, véase, C. E. Reboratti, "Santa Victoria, un caso de aislamiento geográfico", en Desarrollo Económico, Núm. 55 septiembre-diciembre de 1974, Buenos Aires. 
vías de comunicación no trae otra consecuencia que el fortalecimiento de los que detentan el poder local. En Santa Victoria, por ejemplo, los principales beneficiarios del camino de acceso construido en 1962, fueron los comerciantes y el contratista, uno por la facilidad para introducir mercaderías, otro por la rapidez para movilizar a los zafreros. Por ese camino también se fueron los migrantes definitivos, pero no entraron ni el progreso ni la salud: todavía la esperanza de vida al nacer del victoreño es de 37 años, aún mueren una cuarta parte de los niños antes del año de vida, todavía se registra una media de siete hijos por cada mujer y el $98 \%$ de la población muere en la sierra sin atención médica. El problema del desempleo es muy agudo, sobre todo cuando, como en nuestro ejemplo, los mecanismos de acceso a la tierra no apuntan hacia el campesino. Es evidente que si se intenta una reubicación de la mano de obra desplazada por la mecanización de la zafra en su lugar de origen, es necesario cambiar de manera drástica la estructura de tenencia de éste.

Creemos que el caso de Santa Victoria puede aportar alguna luz sobre el complicado problema de las relaciones entre distintas estructuras agrarias, sobre todo cuando estas relaciones se dan a través de movimientos de población. El mismo tipo de movimientos que se producen entre los valles altos y los ingenios en el noroeste de Argentina, se encuentran en casi todo el resto de América Latina.

Por último, es conveniente remarcar que aquí nos encontramos claramente en un tipo de investigación que debe ser tomada en la forma menos sectorizada posible: todo el fenómeno de la migración estacional, para poder ser captado, debe tomarse en su conjunto y no por algunas de sus manifestaciones en forma aislada.

Por otra parte, las migraciones estacionales se encuentran en un proceso de cambio continuo y están indefectiblemente llamadas a desaparecer con el avance de la tecnificación agrícola. Antes que ese momento llegue, es necesario aportar soluciones para esa población que año con año oscila entre sus cultivos tradicionales y el trabajo asalariado. De no hacerlo, nuevos contingentes de población se introducirán en el doloroso círculo de los desplazados. Ya sea en sus lugares de origen, o en los sitios de zafra los trabajadores estacionales deben encontrar un lugar definitivo para vivir. 